\title{
La ciencia procesal latinoamericana: razones de la involución
}

\author{
Latin american procedural science: reasons for involution
}

\section{Pablo Darío Villalba Bernié}

Doctor en Ciencias Jurídicas, Decano de la Facultad de Ciencias Jurídicas en la Universidad Católica, Campus Itapúa, Encarnación, Paraguay, Prof. de Derecho Procesal Civil en la misma Facultad; Profesor de Posgrado en Paraguay y en el exterior en especializaciones, maestrías y doctorados; Presidente de la Asociación Paraguaya de Derecho Procesal Constitucional; Vicepresidente para Sudamérica de la Asociación Mundial de Justicia Constitucional; Miembro del Instituto Iberoamericano de Derecho Procesal; Miembro del Instituto Paraguayo de Derecho Procesal; Presidente del Instituto Itapuense de Derecho Procesal; Secretario General del Colegio de Abogados Procesalistas Latinoamericanos. Conferencista internacional, autor de libros y artículos especializados. E-mail pablo.villalba@uc.edu. py y villalbabernie@gmail.com

Fecha de recepción: Septimebre de 2020

Fecha de aprobación: diciembre de 2020

Para citar este artículo / To reference this article

Villalba, P.D (2020) La ciencia procesal latinoamericana: razones de la involución. Inciso, 22(2) ; 227-246

DOI: http://dx.doi.org/10.18634/incj.22v.1i.1033

\section{Resumen}

El derecho procesal merece ser replanteado al compás de los nuevos vientos que soplan la juridicidad, para de esta manera superar el estado de involución en que se encuentra, aspirando con ello en todo caso el reacondicionar sus pilares principales a partir de nuevos conceptos, pues en el evento en que no sea posible los nubarrones que se ciñen sobre el mismo, no serán superados.

La constante involución del derecho procesal es una problemática actual en Latinoamérica, en donde la construcción de modelos procesales es deficiente y por consiguiente la gestión judicial es una problemática que merece ser tratada con mayor rigurosidad en beneficio del operador judicial como de las autoridades que administran la justicia, pues en caso contrario dichas deficiencias no encontraran una solución a las problemáticas y realidades que ello contrae. 
Por lo anterior, entonces este artículo se ocupará en realizar un estudio exhaustivo de las causales que impiden la evolución del derecho procesal, para finalmente a título de reflexión traer a colación la única manera de superar dicho estadio de regresión permanente de la ciencia procesal.

Palabras clave: procedimiento legal, Derecho, Estado, Administración de justicia, derecho comparado, problema social, legislación.

\begin{abstract}
The procedural law deserves to be rethought to the beat of the new winds that regenerate the juridicity, thus, overcoming the involution state in which it is, aiming to refurbish the main pillars from the new concepts. If the changes are not assimilated, the black clouds that stretch over it, will not be overcome. A constant for Latin America has been the construction of poor models, usually not encompassing the problem of the legal orb. The only way to overcome this state of permanent regression is to conduct a thorough study of the causes that prevent from getting out of the darkness, generated by inefficient procedural models that do not provide satisfaction and well-being in the community where they are established. This reflection article will try to describe where the drawbacks arise from.
\end{abstract}

Keywords: legal procedure, Law, State, Administration of justice, comparative law, social problem, legislation.

\title{
Introducción
}

Analizar a la ciencia procesal latinoamericana no resulta fácil, por la ausencia de similitud de los variados modelos procesales que surgen en las distintas materias, como también por la disparidad relacionada a los repertorios codificados de cada país, de modo que la idea se centrará sobre un intento de justificar las razones y elementos comunes a todas las áreas y fueros, entre ellas dar relevancia al permanente estado de involución o, incluso, de carencia de eficacia, independientemente del modelo procesal adoptado por cada sociedad.

Diseños procesales donde se perciben agudas complejidades y motivos de fuste que avalan la imperiosidad de un mejoramiento de los métodos de juzgamiento. Procesos lentos, engorrosos, burocráticos, con extrema formalidad, sin la adecuada gestión judicial, son algunas de las anormalidades habituales diseminadas en la mayoría de los sistemas imperantes en Latinoamérica.

El Derecho Procesal es entendido como la rama del Derecho que vía conjunto de normas y principios regulan la actividad jurisdiccional del Estado para la concesión de las leyes sustanciales. Su estudio comprende la organización del Poder Judicial, la determinación de la competencia de los funcionarios que la integran, la actuación del juez y las partes en la sustanciación del mecanismo de litigación. 
Frecuentemente se exterioriza que el escenario procesal no funciona como debe ser, brindando respuestas a una sociedad necesitada del correcto servicio de justicia. Ante lo cual, se hace preciso iniciar la observación de los motivos y las razones profundas del estancamiento, dando vueltas en rededor de la idea nuclear que exhibe un sistema procesal involucionado.

Los procesalistas, generalmente apuestan a encontrar las soluciones dentro del Derecho Procesal, quizás aquí se descubra el desliz, pues desde nuestro punto de vista los errores sobrepasan al ámbito procesal, instalándose en la órbita de la cultura jurídica latinoamericana, donde en apariencia somos distintos, pero en el fondo representan idénticos arbotantes culturales. Un recorrido por los órdenes procesales latinoamericanos ha permitido constatar que los problemas son similares en la mayoría de las legislaciones.

Estas circunstancias justifican el abordaje de la investigación con una perspectiva genérica, intentando demostrar que si bien retoña como un dilema procesal, se traslada a un campo más complejo y agudo conllevando a un verdadero problema cultural, que responde a una cosmovisión distintiva sobre como visualizar el mundo jurídico.

El Derecho Procesal con todas sus derivaciones no puede ser mirado como un comportamiento estanco apartado del tronco jurídico, el núcleo procesal deriva del contorno constitucional, debiendo estar integrado al espectro jurídico global.

Así, justificar que primeramente estas condicionantes repercuten sobre la ciencia jurídica, por cuanto el análisis filosófico teórico marca pautas al conglomerado legal, al punto de constituir opciones ideológicas que irradian efectos.

En segundo lugar, repercute sobre la Teoría General del Proceso, indicando noveles arbotantes a ser implantados para consolidar paradigmas evolutivos en busca de una litigación más amplia y efectiva.

Finalmente, tener efectos sobre cada una de las ramas del Derecho Procesal, que deben mirar los mandatos del orden legal tanto externo como interno de mayor jerarquía, acomodando sus variables a estos postulados. Ajustar los presupuestos de la disciplina a coordenadas de relevancia superior, una mirada desde afuera con consecuencias hacia adentro.

Basta recordar que el Derecho Procesal es parte integrante de un todo, que comienza con el marco constitucional y continua con los pilares signados por el proceso supranacional y la convencionalidad donde los derechos humanos cumplen un rol trascendente.

En este orden, gran parte de las deficiencias surgen enmarcadas en posicionamientos que vienen desde afuera de lo procesal, condimentos a los que no se le presta mucha atención. Así a modo ejemplificativo, acaece con aquella que indica sobre la necesidad de designar jueces competentes e idóneos en el Poder Judicial para la correcta prestación del servicio, debiendo estar comprometido con la capacitación permanente de estos futuros buenos jueces. En tal sentido, la formación de la magistratura es vital, ahora bien ¿esta es una cuestión procesal o excede el marco procedimental para posicionarse en la cultura jurídica? Sirva esta pequeña muestra para apreciar que lo procesal no puede continuar siendo extractado como un compartimiento estanco y autosatisfactivo, sino visto como uno integrado al firmamento jurídico en general, que contiene 
innumerables sesgos que influyen para concretar un desarrollo aceptable y convincente.

La evolución constante del derecho y puntualmente del derecho procesal, convertida en ciencia autónoma a principios del Siglo XX, descubre a los juristas abocados en la búsqueda de un modelo procesal más eficaz, práctico y humanizado, que otorgue repuestas adecuadas al hombre y a la sociedad.

\section{Relevancia del Derecho Procesal}

La importancia del derecho procesal es clave para comprender la relevancia de una correcta ordenación jurídica del ámbito procedimental. La transcendencia comprende las siguientes condicionales:

a) Como puntal de la exposición, referenciar que el Derecho Procesal sistematiza el ejercicio de la Soberanía del Estado aplicada a la función jurisdiccional (Devis Echandía, 2002, p. 42), permitiendo prestar un servicio de justicia a los particulares en sus relaciones intersubjetivas, como a las personas jurídicas de derecho privado y a las entidades públicas en sus relaciones con los ciudadanos y entre las distintas reparticiones entre sí. La función jurisdiccional así entendida, se presenta como una dimanación de la Soberanía del Estado.

b) Regula la positivización de una organización judiciaria, con todas las normativas aplicables al procedimiento estipulado, también establece el conjunto de principios que orienta al orden procesal. De nada serviría tener derechos consagrados en los Códigos de Fondo, sin una manera de defenderlos en la práctica, es aquí donde dimana el rol fundamental del Derecho Procesal, favoreciendo el Acceso a la Justicia.

c) Permite la concreción de una verdadera protección a los derechos sustanciales, pasando de la mera consagración, a la verdadera protección efectiva, conjugando teoría y práctica en un mismo orden procedimental. Con ello erradica la posibilidad de justicia por mano propia o justicia privada, obligando a todos los sujetos a someterse a los cánones procedimentales previamente establecidos en nomas procesales.

d) La Tutela Jurídica Efectiva se verifica amparada por el Derecho Procesal, al garantizar un mecanismo de tutela concreta, para que el derecho sustancial pueda consagrarse definitivamente, restableciendo derechos y situaciones jurídicas conculcadas. Se vislumbra que el Derecho sustancial no tendría razón de ser, sin un ámbito procedimental que le augure una segura aplicabilidad, algo así como que de nada serviría tener consagraciones normativas que protejan al derecho de fondo, o a derechos fundamentales (la vida, la integridad, la libertad, la dignidad, los derechos patrimoniales), si se carece de una estructura de protección para esos derechos cuando son conculcados.

Gravita relevante el Derecho Procesal y en específico la función jurisdiccional, cuando mediante las normas procesales garantiza el amparo de los derechos individuales, pasando de la práctica jurídica a la concreción efectiva de la tutela.

Razones primordiales de la involución procesal

Son variadas las razones que exteriorizan los justificativos de la involución procesal, sin 
desconocer los grandes esfuerzos que se hacen para superar los escollos, donde por cierto existen honrosas excepciones a la regla del fracaso, como ser lo acontecido en Uruguay ${ }^{1}$ con el proceso civil; en Chile en el área procesal en general; luego también numerosos países apostando a la transformación como Colombia ${ }^{2}$, Costa $\mathrm{Rica}^{3}$, Bolivia ${ }^{4}$ y Brasil ${ }^{5}$, aunque sin poder afirmar y constatar positividades por lo incipiente aun de la transformación con seguridad el devenir exhibirá si estos cambios fueron acertados.

La descriptiva enumerando las mutaciones muestran procesos de reformas, llevando consigo que lo vigente no cumple con las condicionales de eficiencia, es por ello que se apunta a transformar. Solo basta recordar que la mayoría de los sistemas procesales latinoamericanos responden a la etapa colonialista, afincando sus bases en el Medioevo, razón por la cual la tendencia fue la de un remozamiento general porque aquellos modelos ya no respondían a las urgencias procesales. Fue un lento derrotero evolutivo que aún no ha llegado a todos los países, avalando a un movimiento en ciernes en vías de consolidación.

Las circunstancias referenciadas permiten vislumbrar innumerables aspectos que de manera directa o indirecta afectaron al mundo procesal, entre las que corresponde destacar razones socios jurídicas o, incluso, ubicadas en la ciencia del derecho en general; a más de aquellas prominentemente procesales como las que provienen de la organización judiciaria del servicio que han impedido la concreción del sumo proceso judicial.

La investigación se centrará en los descriptores más trascendentes, reconociendo que no versará sobre la totalidad de los factores, aunque intentará dar un sesgo sobre los de mayor incidencia. Dividir la expositiva, justificando las razones que provienen desde variados bemoles.

\section{Razones socio-jurídicas}

En la postulación acreditar aquellas razones socio-jurídicas, que desde fuera del ámbito de la litigación tienen efectos sobre la eficacia procesal, teniendo por característica no referir a cuestiones internas del método de juzgamiento, sino que refieren a las situaciones que desde extramuros irradian consecuencias sobre el ámbito procesal.

\section{Desconfianza hacia el mecanismo de resolución de conflicto}

Los justiciables no confían en el sistema jurídico en general, menos aún en el procesal, que figura como lento e inservible. Surge aquello que justicia lenta no es justicia, la lentitud atenta contra el servicio, la justicia tardía nunca será justicia, derivando en un alto grado de desconfianza. Sin dudas resulta complicada una mutación basada en estos parámetros.

Sise entiende que el ser humano es tiempo ninguna duda cabe que el procedimiento parsimonioso y pesado no constituye un elemento que contribuya a recuperar la confianza perdida por la sociedad hacia el modelo procesal, consabido resulta que si los procesos duran años el sistema terminará debilitado y por ende la sociedad figurará amenazada por su propia falta de respuesta.

\footnotetext{
1. CóDIGO GENERAL DEL PROCESO, del año 1988, redactado por los mismos autores del Código Procesal Civil Modelo para Iberoamérica, profesores Véscovi, Torello y Gelsi Bidart.

2. CÓDIGO GENERAL DEL PROCESO, Ley 1564, del 12 de julio del 2012.

3. CÓDIGO PROCESAL CIVIL, Ley 9342 , de fecha 01 de diciembre de 2015.

4. CÓDIGO PROCESAL CIVIL, Ley 439, del 19 de noviembre de 2013.

5. CÓDIGO DE PROCESSO CIVIL, Ley 13.105, de fecha 13 de marzo de 2015.
} 
El contexto permite percibir que lo procesal discurre envuelto en un verdadero "drama judicial".

Dentro del catálogo de desconfianza ciudadana sobre el sistema judicial basta con verificar el Barómetro de las Américas ${ }^{6}$, para detectar la deteriorada situación. Se deberían encontrar los motivos, los porqués del fracaso, que llevaron a graficar esa gran desconfianza ciudadana sobre el servicio de justicia. Pesaron más los niveles de corrupción, inmoralidad, mala distribución de los jueces, falta de capacitación de los mismos, carencia de independencia judicial, debilidad institucional (Oteiza, 2018, p 58), entre las causas más destacables que impidieron el logro de confiabilidad deseado.

\section{Masificación del servicio judiciario}

El creciente grado de litigiosidad también actúa como justificativo de la involución, contrastando con la realidad estructural del Poder Judicial, donde se alegan insuficiencia de jueces y falta de funcionarios para resolver los innumerables márgenes de conflictividad presentados.

El sistema procesal atañe ser pensado para futuro, esto implica que al construir un método de juzgamiento deberá tenerse en cuenta que los índices de litigación no disminuirán, sino todo lo contrario, cada vez avanzarán más, fundamentalmente por la existencia de nuevos derechos a proteger.

En la vía procedimental retoñará la implicancia de encausar correctamente los niveles de masificación otorgando respuestas ágiles, si esto no ocurre nuevamente el mecanismo de resolución de conflictos colapsará.

\section{Burocratización judicial}

Se exhibe una tendencia irrestricta al cumplimiento de rituales excesivos, muchas veces caprichosos, augurando al excesivo ritual manifiesto, que no contribuye a la agilización de la solución de los conflictos. De no romperse con la atmósfera de burocracia muy típica del funcionamiento de las instituciones estatales en general, que en grado superlativo abona al Poder Judicial no transigirá la agilización del proceso, porque los gestores de la tramitación del mismo actúan como autómatas cumplidores de esquemas formales absurdos, que en nada condicen ni apuntalan en favor de un método que avance.

Una gran mayoría de diseños procedimentales latinoamericanos sucumbieron ante estos rituales, que lejos de combatirle los admiten y aceptan perdiéndose el fin del proceso. A consecuencia de esta sacralización, el sistema desvaría olvidando sus objetivos esenciales, como lo son el hallazgo de verdad y la concreción de justicia.

\section{Razones extrínsecas situadas en la ciencia del derecho}

Asimismo, contribuyen para la regresión razones externas como las teóricas con derivación filosófica, que a consecuencia de su incomprensión no han refrendado que la ciencia jurídica de estos lares pueda evolucionar correctamente; como también la incidencia de los Derechos Humanos y la idea de Estado Social de Derecho.

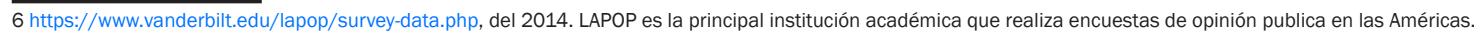




\section{Confusión ius filosófica}

Discurre la cuestión por una gran confusión de filosofía jurídica, que tendrá que ser clarificada con el objetivo de avanzar. El proceso ha estado sometido desde siempre al yugo positivista radical que no condice con la visión de los Derechos Humanos, precisando ser superada para generar un avance cualitativo, de lo contrario se proseguirá con posicionamientos asistémicos de difícil comprensión. La ciencia procesal anclada en el positivismo, en cambio, los nuevos arbotantes de Derechos Humanos y convencionalidad atrincherados en teorías cuanto menos no positivistas. Una auténtica crisis ius filosófica, una verdadera contradicción que precisa ser analizada a profundidad.

Corresponde clarificar los posicionamientos teóricos de otra manera los inconvenientes plantearán la encrucijada de disímiles visiones, por la sencilla circunstancia de provenir de senderos filosóficos diferentes. Desde siempre fue sostenido, que el derecho procesal debe pasar por un filtro teórico, lo contrario avalaría a institutos contrapuestos con la solución requerida o, cuanto menos, con soluciones no viables. La realidad esboza una mezcla de criterios e institutos procesales, que en gran medida tienen otro recuento jurídico a los requeridos.

\section{Incidencia de los Derechos Humanos}

Repercute vital en este tiempo la gran incidencia de los Derechos Humanos sobre el orden interno y el procesal en particular a través del control de convencionalidad, indicando que el norte es el arribo a la justicia. Un modelo procesal que debe garantizar el valor justicia, en detrimento de la seguridad jurídica (propia del legalismo).

El quehacer procesal se ha visto transformado en estos tiempos a consecuencia del dinamismo adquirido por el derecho que permanentemente plantea nuevos retos y problemas a resolver, en especial al postular la internacionalización de los derechos humanos, exhibiendo que variadas figuras procesales son comunes a todos los diseños jurídicos.

En un rescate por la humanización del derecho todo el sistema jurídico debe estar orientado en salvaguardar los derechos de las personas como tal, es la razón de ser y fin último del derecho, que no tendría razón de existencialidad sin la persona humana. Ni el Ejecutivo, ni el Parlamento, ni el Poder Judicial pueden dejar de lado estos axiomas primordiales.

De modo, que un primer aspecto del ensanchamiento de las fronteras, reposa atinado por el necesario rescate del ser humano por sobre toda otra cuestión, con irradiaciones derivadas hacia el modelo procesal.

Desde los derechos humanos se postula el pacta sunt servanda que a consecuencia de la Convención de Viena sobre Derecho de los Tratados invita a que el contorno jurídico sea interpretado de buena fe, instando a no debilitar el sistema.

En consecuencia, el equilibrio hermenéutico se obtiene orientando en el sentido más favorable al destinatario de la protección internacional. Como ha reiterado la Corte IDH: "Tanto esta Corte (...) como la Corte Europea de Derechos Humanos (...) han señalado que los tratados de derechos humanos son instrumentos vivos, cuya interpretación tiene que acompañar la evolución de los 
tiempos y las condiciones de vida actuales"?.

Comprender los efectos procesales derivados de los derechos humanos producto del diálogo existente entre ambos órdenes, en especial porque las diferencias tienen que superarse, donde el control de convencionalidad asume un rol preponderante, que como creación pretoriana germina en el entorno de la Corte IDH, ya sea para aplicar la Convención Americana a los casos jurisprudenciales a resolver en la instancia interamericana, como para instar su aplicabilidad a los jueces internos de cada uno de los países signatarios de la Convención ADH.

Los derechos humanos como nuevo paradigma jurídico, apuntan a reconstruir la confianza social en la Ley y la Justicia (Vega, 2008, p. 59), basado en un plexo de legalidad que condiciona y obliga a los Estados a respetar a los seres humanos sometidos a su jurisdicción en estándares jurídicos mínimos en materia de derechos y garantías individuales, cuya protección comienza con la norma constitucional.

Estas connotaciones terminan influyendo en el derecho interno, exhibiendo una repercusión sobre las normas jurídicas domésticas y, en esa dinámica, sobre el sistema procesal, con el fin de otorgar una máxima protección al ser humano.

\section{Falta de comprensión de la idea del Estado Social de Derecho}

La mayoría de las legislaciones constitucionales latinoamericanas han realizado una apuesta con el fin de consolidar la noción del Estado Social de Derecho, que refleja como un nuevo reto a conquistar. Invita a dejar atrás la visión del Estado de Derecho que tenía una clara raigambre liberal, burguesa y positivista, reemplazada por la doctrina del Estado Social de Derecho que tiene como fin rescatar la dignidad humana y un catálogo de principios que invitan a analizar al proceso desde una visión solidaria y cooperacioncita. Un modelo procesal pensado en la socialización del mecanismo de litigación, superando al porte individual de antaño.

A partir de la concepción del estado social de derecho se convierte al proceso en un ámbito social, implica una forma de litigación con ascendencia de lo social donde todos los sujetos procesales confluyan para dirimir el conflicto llevado ante la jurisdicción, superando al interés de partes por una concepción donde también adquiere trascendencia el Estado por medio de los jueces (Pabón Giraldo, 2017, p. 522).

\section{Razones prominentemente procesales}

En cuanto a las razones procesales de la involución se presentan varias, que con seguridad no serán todas, pero se intentará englobar a las principales.

\section{Crisis normativa}

Corresponde indagar sobre la prognosis legislativa desde donde analizar el repertorio procesal, con el fin de mejorarlo. Naturalmente exterioriza, que para optimizar el mecanismo de juzgamiento hay que reformar la ley procesal, si bien la afirmación no consiste en hacer denotar un error absoluto de lo vigente, cabe acentuar que la sola modificación legal o reforma parcial resultará

7. Corte IDH, Caso Villagrán Morales y otros (Casos de los Niños de la calle) vs Guatemala, Sentencia del 19/11/1999 (Ser. C), № 63 , párr. 193. 
insuficiente, es apenas el punto de partida. Sin rodeos, se tendrá que apostar por una incipiente y adecuada legislación. Radica en una falacia que con solo reformar la ley el cambio se producirá automáticamente.

Los diagnósticos procesales avizorarán sobre la necesidad o no de una reforma, que al advertir que el proceso proviene de antiquísimas visiones procesales, sin divagaciones la reforma debería ser la conclusión a la que se arribe. Ahora bien, también es cierto que no es suficiente con reformar una norma procesal, en tal sentido el nuevo ordenamiento procesal deberá estar acondicionado a las necesidades que cada localismo indique; asimismo, ajustarse a los cánones propiciadores de las nuevas visiones procesales, de no presentarse estas circunstancias su implementación con éxito, estará en duda.

\section{Oralización del proceso un mito}

Realizar un convite por la oralización del procedimiento, vía proceso por audiencia, teniendo en cuenta que la litigación oral consiste en uno de los mecanismos más idóneos para la resolución del conflicto, asintiendo que en una inmediación entre el juez, las partes y los terceros, el órgano jurisdiccional resuelva la casuística.

La garantía de un intercambio verbal de argumentos que conlleva diálogos, prueba, alegatos frente al juez, consiste en el mejor medio conocido por la humanidad para dirimir conflictos. Sin embargo, corresponde cuestionarse si lo buscado es realmente un proceso oral. En tal sentido reflexionar, que aquello propiciado como un eximio sistema procesal es el proceso mixto por audiencias, mezcla de lo mejor de la oralidad con lo mejor de la escritura.

Entonces, la denominación de proceso oral es aquel que garantice una audiencia de debate reproducida en forma verbal, esto significa, que la garantía de oralidad emerge concretada para el momento de recepción probatoria.

Dependerá de la forma de concebir este juicio oral si el mismo resulta o no efectivo, apuntando tanto a lo que implica la organización judiciaria como a la compresión de todos los gestores de la nueva cultura del litigio. Será un mito el juicio verbal si la oralidad no conlleva la concreción de los principios de concentración, inmediación, contradicción, publicidad y celeridad.

Como todo mecanismo de resolución de conflicto tendrá sus defectos y virtudes, pero lo esencial consistirá en concretar la funcionalidad de la actividad jurisdiccional enmarcadas en un sistema oralizado como método de concreción de una correcta tutela.

No solo bregar por oralidad, sino pregonar el respeto a las garantías fundamentales, la desburocratización, desformalización, simplificación procedimental, inmediatez, presencia del juez en la sustanciación del pleito y respeto al plazo razonable. Difícilmente con un diseño escriturario se logrará un proceso eficaz, las estadísticas son contundentes en tal sentido.

\section{Razones externas referidas a la organización}

Desde una perspectiva externa al diseño procesal, también inciden factores que contribuyen a la falta de desarrollo de la ciencia procesal. 


\section{Ineficiencia Procesal}

La ineficiencia contrasta con la eficiencia procesal, esta última representada en la estructuración del servicio, esa gran maquinaria del Poder Judicial que deberá ser capaz de evolucionar adecuándola a los tiempos actuales. Recordando que la eficiencia procesal no es atributo ni de la escritura, ni de la oralidad, sino de un comportamiento estructural de todo el Poder Judicial volcado en lograr que el diseño (sea cual fuere) resulte virtuoso.

Fue un error común concebir que con el solo cambio hacia el proceso oral fuera suficiente para la aptitud e idoneidad del método de litigación, resulta patente que con la oralidad no basta. El ideal de eficiencia aflora al explotar a cada una de las formas en su mejor repertorio en favor del eximio proceso, la escritura en la parte introductoria, la oral para el debate de la causa.

\section{El gran déficit, la gestión judicial}

La crisis del proceso se encuentra en la deficitaria gestión judicial. Si bien es cierto, que el proceso oralizado alcanza grados de superioridad respecto del juicio escriturario, no obstante, resulta insuficiente garantizar que únicamente con la oralidad se tendrá un servicio superlativo, esto fue comprobado en varias legislaciones que no apostaron a estructurar correctamente el funcionamiento del método de juzgamiento.

De un tiempo a esta parte, se recalca la importancia de la denominada "Gestión Judicial", transmitiendo la noción de proveer las condicionales necesarias para que el diseño procesal tenga una funcionalidad adecuada (sea vía procedimiento oral o escriturario). Representa a todo aquello que responde a la organización procedimental con una mirada desde fuera del proceso (Villalba Bernié, 2019, p. 708), es decir, la respuesta que genera el contorno judiciario a los nuevos fenómenos propuestos por el derecho procesal, que generalmente tiene centrada su apuesta en el juicio oral.

Agudos estudios demostraron que la mayoría de los sistemas procesales donde fueron detectados grandes defectos de funcionamiento, naufragaron a consecuencia de una deficiente "gestión judicial". Subrayar este hecho a propósito, tratando de explicitar claramente la cuestión, los procedimientos no fracasan por la oralidad o por la escritura, sino lo hacen por adolecer de defectos en la elaboración de soluciones que apuesten hacia la agilización del sistema.

La profesionalización de la gestión tribunalicia vía "gerencia judicial", en un medio para que actuando desde fuera de los juzgados coadyuvando con el despacho judicial-administrativo, en una tendencia a destacar, no solo en los procedimientos orales sino en todo tipo de litigación, cooperando para un mejor servicio. El rol de juzgar, no debería residir entremezclado con el rol que concierne a las actividades de gestión (Pereira Campos, 2010, p. 1004) correspondiendo separarse, previendo que el juzgador solo obre para sentenciar.

La mayor cantidad de tiempo en el proceso se consume en la gestión, de modo que no deviene necesario acortar los plazos, sino mejorar la actuación de los tribunales en el quehacer extra procesum. Es un mito acelerar el procedimiento con la reducción de plazos. 
Aún más, una vez mejorada la gestión no debe abandonarse, encadena un trabajo constante de modernización, anuda una obra permanente que no culmina nunca, solo así el servicio estará actualizado. Ir adaptando sin pausas los beneficios de las nuevas tecnologías, haciendo que las variables sean dinámicas, de lo contrario, se modernizará para en algún momento volver a saturarse, degenerando reiteradamente en un diseño deficitario, sea escrito u oral.

Corresponde tener en cuenta aspectos esenciales, como ser:

a) Gerenciamiento judicial;

b) Efectiva distribución de casos;

c) Tecnificación de las audiencias;

d) Lograr la mayor desburocratización posible del proceso;

e) Correcta selección de jueces y preparación de funcionarios judiciales;

f) Establecer reglas e indicadores básicos para lograr parámetros de eficiencia en cada juzgado;

g) Dotar de estructuras edilicias adecuadas, para el correcto funcionamiento del diseño de litigación propuesto;

h) Incorporación de tecnología a los distintos modelos procesales.

Fue demostrado también, que incide negativamente la no ejecución de las políticas públicas tendientes a consolidar una gestión correcta, trasuntando la noción de proveer todas las condicionales para que el diseño de litigación tenga funcionalidad.

La mayoría de los sistemas procesales fracasan por defectos de funcionamiento, a consecuencia de una deficiente gestión judicial. Tendrán que brindarse las condicionales técnicas, financieras y de capacitación para garantizar que el método sea comprendido, a partir de allí una vez asimiladas sus directivas, bregar por el logro de eficacia.

\section{Resumen}

En apretada síntesis, fueron descriptos los factores más trascendentes de la involución, que deberán ser clarificados en algunos casos y superados en otros, para lograr el ansiado supremo proceso. Nótese que constituye un error diagnosticar que toda la problemática se solucionará atacando al Derecho Procesal, por cuanto la graficación excede al exclusivo campo procesal, exigiendo una verdadera mutación cultural. Sin embargo, todavía quedan otras consideraciones por efectuar, que serán esbozadas en los tópicos posteriores.

\section{Otros factores que inciden en el desarrollo del derecho procesal}

Corresponde abordar otras consideraciones que requieren de reflexión, en cuanto a su incidencia sobre el derecho procesal, pues las consideraciones no se reducen a las explicitadas con anterioridad. 


\section{Constitucionalización y neoprocesalismo}

La falta de asimilación de las ideas de constitucionalización del orden jurídico también ha incidido para que el derecho procesal no pueda rotular un avance en la defensa de los derechos fundamentales, Latinoamérica exhibe una gran deuda en materia de justicia constitucional, o lo que es lo mismo, un derecho procesal estructurado en consonancia con la defensa de los derechos constitucionales.

Al conjuro de la Constitucionalización del orden jurídico ${ }^{8}$, se consolida un alejamiento de las tendencias positivistas. Esta constitucionalización consiste en la marcha y resultado de la transformación del Derecho causado por la Constitución (García Figueroa, 2005, p. 163), conllevando la impregnación de todo el espectro jurídico por las normas constitucionales.

Como derivación de la constitucionalización resulta la idea de un "Neoprocesalimo", como devenir lógico que plantea el reformulamiento de la teoría general del proceso judicial. La mutación propiciada resulta tan profunda que corresponde analizar en retrospectiva conceptos resaltantes del Derecho Procesal como la acción, la jurisdicción y los mismísimos postulados del proceso, para ajustarlos al novel neoprocesalismo.

La intromisión de la nueva teoría constitucional que es invasora del orden legal de menor jerarquía, obliga a reconsiderar conceptos básicos de la doctrina procesal, transformando la teoría del proceso, o por lo menos se halla en camino de hacerlo. El neoprocesalismo contemporáneo, en términos genéricos consiste en la constitucionalización del ordenamiento jurídico procesal.

De hecho, esa influencia del constitucionalismo sobre el proceso, se plasma a partir de la idea que debe descartarse algún área del derecho que pueda evadir la influencia constitucional, así cualquier aspecto del orden jurídico no debería escapar del radio de acción de las garantías fundamentales. Visto de una manera sencilla, discurre en ajustar vetustos conceptos constitucionales y procesales en favor de una mejor tutela de los derechos fundamentales.

Con las aclaraciones previas, sostener:

a) El neoprocesalismo no es otra cosa que la constitucionalización del orden jurídico procesal, trasluce al Derecho Procesal visto a través del prisma de la Constitución y los derechos fundamentales.

b) El enfoque neoprocesalista muestra una jurisdicción que ha ampliado sus deberes cuestionando los límites de la tutela judicial efectiva, no limitado exclusivamente a la defensa de los derechos, sino sustentado en argumentos y principios.

c) La vigencia de un "derecho procesal sobre principios", plantea una mirada axiológica que supera la mera subsunción (deontología), llevando a comprender, que los principios son precedentes para quien resulte ser el intérprete de la disputa jurisdiccional, en consecuencia, eje esencial en la concreción de justicia.

d) Como una cuestión extramuros, fluye el embate de los derechos humanos que condicionan

8. También denominado "Neoconstitucionalismo". 
el panorama de la esfera procesal, propiciando orientadores del ámbito internacional a aplicarse en el orden doméstico, puntualmente en el ámbito procesal.

e) La idea procesal en estos tiempos supera al derecho procesal clásico y tradicional basada en el agotamiento en la regla como en la norma (proceso deóntico), superando y reemplazándola por otra más abierta y dinámica de una connotación ius fundamentalista, que exige principios, valores y argumentación, dejando atrás al positivismo lógico jurídico por una visión no positivista racional y argumentativa.

f) Lógicamente a consecuencia de las formulaciones que anteceden, se nota un cuestionamiento relevante a la visión de los Códigos Procesales Legalistas que tendrán que ser superados, puntualmente cuando estos repertorios aparecen encerrados en sí mismos, al extremo de referenciar que los casos dudosos o cuestiones no contempladas se resolverán por los principios consagrados en el propio Código Procesal limitando la labor del intérprete, ello es equivocado, porque como sostenemos se da una constitucionalización del orden procesal, los principios y valores tienen que ser aplicados a partir de la Constitución y el Bloque de Constitucionalidad, desde allí descender a los Códigos Procesales y no al revés. En otros términos, comprender que lo fundamental no está en los códigos, específicamente en los procesales, sino en la norma constitucional y la supranacional que orientan el accionar de todo el orden interno.

\section{El avance convencional}

\section{Lineamientos generales}

El ámbito procesal moderno no puede soslayar la visión convencional, buscando su complementación y concreción en cada legislación, de no hacerlo se exhibirá como un repertorio de litigación rezagado. Lo procesal desde la visión internacional, no es más que la operatividad de modelos judiciarios propiciadores de una justicia para todos en forma igualitaria, pero no solo en el contexto interno de cada país, sino en el globalizado a nivel mundial. Los derechos humanos han comenzado a trasponer las barreras impuestas por cada legislación interna, insertándose desde lo transnacional hacia lo nacional, generando una mutación cultural en los diversos países, al divisar como parte de lo suyo aquello que era pregonado desde fuera de sus fronteras, al fin de cuentas los derechos humanos pasaron a ser parte del derecho positivo interno de cada país.

Esa internacionalización de los derechos procesales, tiene la virtualidad de influir en forma directa en el ámbito procesal, obligando que las legislaciones adapten su normativa, asimilando las instituciones pregonadas desde lo supranacional ${ }^{9}$.

Trátese de asegurar por la vía procedimental, la aplicación efectiva de los derechos humanos, propiciando un equilibrio entre los miembros de la sociedad democrática inmersos en un Estado Social de Derecho, armonizando las relaciones entre los poderes públicos y las vinculaciones con los particulares. Al decir de Perez Luño (2006, p. 37), el status activus processualis deviene en un factor clave para asegurar el ejercicio pleno de todas las libertades.

9. Corte IDH, Caso Hilaire, Constantine y Benjamin y otros, sentencia 21 de junio de 2002. Afirmaba: “El Estado debe remover todos los obstáculos que puedan existir para que los ciudadanos puedan disfrutar de los derechos que la Convención reconoce. Por consiguiente, la tolerancia del Estado a circunstancias o condiciones que impidan a los individuos acceder a los recursos internos adecuados para proteger sus derechos, constituye una violación del Art. 1.1. de la Convención". 
La importancia de las formas procedimentales, engalanadas como signos emblemáticos del derecho al proceso y de tutela jurídica efectiva, se hallan comprometidas con la creciente difusión de las instituciones de protección, que de otra manera no podrían tener consolidación efectiva, siendo una garantía de salvaguarda de los derechos fundamentales. El desafío de este tiempo, compromete la nacionalización de los derechos universales (derechos humanos) y su intromisión en el orden interno como la única vía eficaz para concretarlos, de allí que los orientadores procedimentales evocan un papel trascendental para la asimilación irreversible de los derechos reconocidos.

América Latina se muestra como el continente donde el control de convencionalidad ha adquirido un vuelo propio, desde nuestro particular punto de vista, a consecuencia de la carencia de marcos teóricos de referencia constitucional y procesal ${ }^{10}$, una situación negativa (falta de ius filosofía), convertida en positiva a la luz de la teoría convencional.

El Control de Convencionalidad responde a doctrina de la Corte IDH al manifestar que los juzgadores deben hacer un cotejo entre la norma convencional y la norma interna para verificar la conformidad de ésta con el tratado internacional, idéntica al control de constitucionalidad pero que concreta la aplicabilidad de la Convención Americana de Derechos Humanos, en cambio el control de constitucionalidad versa sobre el cumplimiento de la Constitución Nacional en el caso en concreto.

Actúa el control de convencionalidad, sustituyendo, a la Constitución como parámetro único de validez, en el tema puntual de los derechos humanos, colocándose en el grado superior de la escala jerárquica normativa de los sistemas constitucionales de la región. El contorno procesal moderno imbuido de condimentos convencionales, que señalan el derrotero de una aguda metamorfosis.

Emerge como un mandato solidificado hacia el orden interno, obligando a los jueces y al Poder Judicial adecuen su accionar a los postulados de la Convención, materializando en los casos concretos las garantías fundamentales consagradas del ámbito internacional, en un control de convencionalidad difuso exhortando a cumplir en todos los fueros y especialidades las regulaciones de protección previstas desde el sistema supranacional.

\section{Los ciclos de la convencionalidad}

Infiere trascendente explicitar los ciclos de la evolución convencional porque constituye un mandato a todas las autoridades estatales, no solo los jueces están obligados sino todo el aparato estatal.

Resaltar que en una primera etapa el control de convencionalidad fue en principio jurisdiccional, instando la propia Corte IDH su aplicación, como también a los jueces nacionales de los distintos fueros en el orden interno.

10. Europa en cambio, no han dado estas circunstancias por lo que la incidencia de los órganos internacionales de Derechos Humanos y de la doctrina del Control de convencionalidad no ha proliferado con la magnitud que se da en el continente americano, donde la característica es que si bien se apuntala el respeto de las garantías fundamentales se concreta por vía de la jurisdicción constitucional interna y no por el control de convencionalidad, que es mirado con cierto recelo. No obstante recalcar la gran trascendencia del Tribunal Europeo de Derechos Humanos y el alto grado de cumplimiento de las sentencias por los Estados signatarios del Convenio Europeo, situación que contrasta con Latinoamérica. 
Una segunda etapa, en función de la competencia de los órganos judiciales y en virtud del despliegue de operatividad de esa competencia (principio de legalidad). La función de Control de Convencionalidad resultó en la construcción internacional de un "corpus iuris" un derecho común.

Una tercera etapa, exhibiendo la aplicabilidad reservada a los órganos auxiliares de la justicia, quienes son los gestores de la función judicial y administrativa (Actuarios, Ministerio Público, etc.).

Una cuarta etapa, que involucra a todos los órganos y agentes del Estado abriendo el horizonte de manera extendida (Ejecutivo, Legislativo, todos).

Comprender que no se dice "acatamiento", que implica un cumplimiento imperativo, sino que se reflexiona sobre un "control" de convencionalidad que tendrá que ser efectuado en cada caso en particular aplicando la norma más benéfica para la protección de la persona humana.

La bitácora de la convencionalidad, produce el fenómeno de una ampliación de las fronteras del Derecho Procesal, rebasando los originarios posicionamientos que fueran proyectados por doctrinarios que desde antaño vienen realizando investigaciones sobre el tema. El Derecho Procesal, ya no puede ser mirado con una visualización restringida, pues su dinamicidad concibe el reformulamiento constante de sus límites y contenidos, en una visión amplia no restrictiva, solo así acomodarse a las necesidades de la comunidad donde está vigente.

\section{El proceso como un enfoque de derecho público}

Definitivamente para superar el estado de involución se requiere comprender que el método procesal ha pasado de una concepción privatista a una concepción pública, que irradia efectos a todas las esferas y materias de la teoría general del proceso. Por un lado, la visión constitucional del Estado Social de Derecho invita a una mirada socializante del mecanismo de litigación que impone un compromiso a todos los gestores del entorno judiciario a comprometerse con la obtención del resultado buscado por el mecanismo, cual es justicia y verdad. Desde este marco jueces, partes e intervinientes del proceso en favor del vínculo con un enfoque renovador.

Por otro lado, corresponde abandonar esa vieja disyuntiva que vinculaba al modelo procesal privatista con el principio dispositivo y al publicista con una concepción inquisitiva, siendo una apreciación que no condice con la realidad actual. Consabido resulta, que el derrotero evolutivo del derecho procesal ha pasado por varias etapas, una de ellas sin lugar a dudas representativa de una conquista liberal fue la del proceso privatista, casi siempre vinculado al proceso civil. En este tiempo a partir de la transformación del pensamiento jurídico que se origina con la posguerra, la mayoría de las legislaciones abandonan la tendencia privatista, así ha sucedido con los países europeos del civil law, como con Gran Bretaña (1995) y Estados Unidos (reforma de 1990) en el common law, siendo una secuencia repetida por doquier. Se consolida de esta forma la posición publicista, con tendencia a reconocer un alto grado de socialización al proceso y con una gran incidencia de la Magistratura, convirtiendo al Juez en director del proceso. 
Este proceso de publicización que trasciende fronteras por la gran efectividad que genera, no corresponde sea equiparado con un resabio inquisitivo sino como un modelo que tiende a morigerar los efectos negativos del sistema privatístico-dispositivo, en definitiva, desde los marcos constitucionales etiquetar una ascendencia en el sentido de avalar una clara intromisión estatal, preocupada por aquello que considera como derecho público.

Si bien es cierto puedan existir discrepancias sobre la concepción pública del proceso, cuanto menos se advierte con claridad que el mismo asume cuanto menos una contextura mixta. De no apreciar la relevancia de estas connotaciones proseguirán los errores, al visualizar al proceso como privado, instando a construir un modelo procesal equilibrado mezcla de lo público con lo privado, donde no se rompan las garantías fundamentales de las partes, ni el objetivo final del proceso que consiste en el logro de justicia.

\section{La necesidad de concretar la tutela judicial efectiva}

Gran impacto sobre el derecho procesal y su estado involutivo tiene la noción de tutela judicial efectiva, pagando un alto costo de credibilidad el Derecho Procesal como secuela de su carencia de consolidación. Resulta vital para el ámbito procesal identificar las connotaciones de la idea de una tutela judicial efectiva, so pretexto de no hacerlo se caería indefectiblemente en una visión restringida y formalística del proceso.

Destacar el estrecho ligamen que tienen las ideas de "acceso a la justicia" con la de "tutela jurídica efectiva”, reconociendo que ésta última es más englobante que la primera. Así, la tutela judicial efectiva abarca: a) el derecho de acceso a los tribunales; b) el derecho a obtener una sentencia fundada en los hechos y el derecho correspondiente; c) el derecho a la efectividad de la sentencia o de las resoluciones judiciales; y, finalmente, d) el derecho a un recurso previsto en el orden legal.

El derecho a la tutela jurisdiccional efectiva comprende: una tutela jurisdiccional en primer grado, que alcanza al acceso a la jurisdicción; una tutela jurisdiccional en segundo grado, que encierra la prioridad de obtener una respuesta que resuelva el conflicto, que a su vez esté fundada en derecho; $y$, una tutela jurisdiccional de tercer grado, constriñendo que la respuesta otorgada por el órgano jurisdiccional sea susceptible de ser ejecutada. El grado determina la efectividad del derecho, que en conjunto es elevado al rango constitucional y, por lo tanto, genera en el Estado una protección especial a través de las garantías constitucionales cuando se percibe una lesión en cualquiera de esos grados, además de la obligación de fomento de la tutela derecho en oposición a formas restrictivas de visualización del derecho a la tutela judicial efectiva.

El derecho de tutela jurisdiccional efectiva, aparece adherida a determinados conceptos como el de acceso a la justicia y a su derivado el derecho de acción, teniendo una evidente connotación constitucional, transigiendo una bifurcación procesal cuyo propósito consiste en cautelar una justa protección de derechos fundamentales, actuando como un pilar para la construcción del debido proceso con garantías constitucionales e, incluso, convencionales a tenor de lo dispuesto en el Art. 25.1. de la Convención ADH, que alienta la posibilidad de acceder a un recurso efectivo para la protección de los derechos. 
Ahora bien, la tutela judicial efectiva supone que toda pretensión deducida sea ante órganos jurisdiccionales independientes e imparciales, presuponiendo la proscripción de los elementos enervantes del sentido favorable a la pretensión.

En el caso Ortiz Hernández y otros vs Venezuela (2017) emitida por la Corte IDH, se reflexionaba sobre la tutela jurídica efectiva, en el sentido de exigir su cumplimiento a los jueces nacionales, en los siguientes términos: "Además, este Tribunal ha señalado que "el derecho a la tutela judicial efectiva exige a los jueces que dirijan el proceso de modo a evitar que dilaciones y entorpecimientos indebidos conduzcan a la impunidad, frustrando así la debida protección judicial de los derechos humanos", y que "los jueces como rectores del proceso tienen el deber de dirigir y encauzar el procedimiento judicial con el fin de no sacrificar la justicia y el debido proceso legal en pro del formalismo y la impunidad", pues de lo contrario "se conduce a la violación de la obligación internacional del Estado de prevenir y proteger los derechos humanos y menoscaba el derecho de la víctima y de sus familiares a saber la verdad de lo sucedido, a que se identifique y se sancione a todos los responsables y a obtener las consecuentes reparaciones". ${ }^{11}$

En consecuencia, al referenciar a la tutela judicial efectiva, indirectamente se indica el cumplimiento del debido proceso, de la argumentación jurídica, de la necesidad de un proceso público, que otorgue garantías de cumplimiento. Engloba la mayoría de los condimentos puntuales a ser cumplidos en el Derecho Procesal.

\section{Eficiencia sin ideología: una quimera}

A la luz del Sistema Interamericano de Derechos Humanos se ha exteriorizado como característica principal, la necesidad de rediseñar la posición ideológica de los gestores del nuevo rumbo procesal, so pena que de repulsar su concreción versaría sobre un proyecto infructuoso que caería nuevamente en las deficiencias de las que se intenta escapar. Produce una transformación profunda en la interpretación del Derecho, avasallando el liberalismo constitucional, reemplazándola por otra visión de constitucionalismo social concebida sobre la base de un equilibrio entre lo económico y lo social.

Cuadra notar, que se produce una íntima relación entre el debido proceso y la "justicia basada en principios", pues todo el plexo legal acondicionado a los principios que actúan como rectores del orden jurídico. Sobresale la idea de un Debido Proceso apuntalado por principios, no ya limitado por las reglas, haciendo que los principios cardinales sirvan de guía para la consolidación del due process of law.

El planteamiento ideológico denota la superación de un viejo esquema que responde a un legalismo antiguo, por otra ideología que sugiere una renovación de los conceptos jurídicos promoviendo un novel modelo de Constitucionalismo, de Derecho Procesal y de democracia.

Siguiendo aquello que no hay nada más práctico que ser teóricos, rotula un compromiso con la visión ideológica de este tiempo, en una mirada ius filosófica a ser abordado al compás de los vientos renovadores de humanización de la ciencia jurídica, que incide sobre el derecho procesal. No en balde se afirma que la eficiencia sin ideología es una quimera, tal como el barco

11. Corte IDH, caso Ortiz Hernández y otros vs Venezuela, Sentencia 22 de agosto de 2017, párr.145. 
a la deriva (navega sin rumbo), porque la ideología le pone contenido teórico al desarrollo de las innovaciones procesales. El soporte ideológico resulta vital para diseñar el razonamiento procesal, en el convencimiento que el nuevo milenio propone la superación de anquilosadas concepciones.

\section{Gran repercusión del Poder Judicial}

También resulta necesario discernir que para salir del estado de letargo involutivo se tendrá que comprender los móviles en cuanto a la magnitud adquirida por el Poder Judicial. Los últimos tiempos, especialmente Latinoamérica ha visto trastornada la visión por un cambio de paradigma profundo, pocas veces advertida, al adquirir gran trascendencia la magistratura, suponiendo el crecimiento cualitativo del Poder Judicial, que contrae un predicamento incluso superior a los otros poderes del Estado (Legislativo y Ejecutivo), proyectando una variable en cuanto al eje de prelación de la tradicional división de poderes de Montesquieu.

Así como los siglos XVIII y XIX fueron del surgimiento y hegemonía del Parlamento, trasuntado a la luz de la Revolución Americana, luego la más trascedente Revolución Francesa, eminentemente Parlamentaria; el siglo XX en cambio, mudó la visión parlamentarista, reemplazándola por una clara relevancia del Poder Ejecutivo, donde las ideas del Presidencialismo y de un agudo caudillismo socavaron los cimientos Parlamentarios, que fueron puestos al servicio del gobernante de turno; sin embargo, el siglo XXI, asoma floreciente con la idea de un gran predominio del Poder Judicial, que puede palparse permanentemente ante la notabilidad adquirida por el denominado "gobierno de los jueces" proveniente de la connotación de política social que viene inmersa en la actuación de los magistrados.

Procedente de la descriptiva, denotar que los conceptos tradicionales son cuestionados y acomodados a las necesidades sociales, no debiendo sorprender la vital trascendencia adquirida por el Poder Judicial, como alternativa de equilibrio en algunos casos en la protección de los derechos fundamentales, en especial cuando son violentados por otros poderes del Estado. Las consideraciones precedentes invitan a concretar un modelo procesal basado en la actuación de los órganos jurisdiccionales. De una buena vez se tiene que comprender que el proceso debe construirse sobre arbotantes de justicia y solidaridad, convirtiendo al juez en gestionador del resultado del proceso, donde tendrá que bregar por el logro de justicia, sin dejar de lado las garantías de las partes, en un sistema equilibrado.

\section{Desenlace}

Lo narrado expone la necesidad de un nuevo miramiento sobre las condiciones en que debe desarrollarse el Derecho Procesal, acondicionando sus pilares esenciales a bisoños postulados que miran al diseño basado en otras condicionales para hacerlo eficaz, entre ellas la convencionalidad y la correcta gestión judicial.

De no adaptarse a las nóveles requisitorias tanto estructurales como de derechos humanos, representará un contorno procesal con un mar de debilidades que no se amoldará a las exigencias de la sociedad moderna, la que evoluciona en el sentido de una visión proteccionista. 
El relacionamiento entre lo constitucional y lo supranacional acaba exteriorizando efectos sobre el Derecho Procesal, porque aquello que se mantiene en las altas esferas convencionales y constitucionales requiere de una bajada de línea al procesalismo, que es el lugar natural donde se cumplimenta efectivamente la tutela de los derechos. De ahí que devienen trascendentes los ajustes a ser realizados en el derecho procesal, en todas sus áreas y materias, con el objeto que el mecanismo de acción concuerde con las incipientes condicionales.

La doctrina desde hace tiempo ha venido vitalizando la relevancia de la problemática procesal, como un componente primordial del amparo de los derechos. Así las cosas, se busca que los derechos pasen de la exhibición teórica, a la realidad de la concreción en la práctica, que únicamente se viabilizará mediante un efectivo Derecho Procesal.

Llegó la hora de remozar al Derecho Procesal ajustándole a los nuevos cánones evolutivos, lo contrario significaría continuar con el estado de la involución que por variadas circunstancias se exteriorizan, por cierto, situación vigente desde siempre en Latinoamérica. El futuro obliga a reformular los criterios construyendo un escenario procesal que otorgue respuestas a una sociedad necesitada de un correcto mecanismo de resolución de conflictos. Al fin implica concebir un ámbito procesal correcto y efectivo, allí donde los fracasos han marcado el derrotero.

\section{Referencias bibliográficas}

Devis Echandía, H. (2002). Teoría General del Proceso, $3^{\circ}$ Edición, revisada y corregida, Editorial Universidad, Buenos Aires, Argentina.

García Figueroa, A. (2005). La teoría del derecho en tiempos de constitucionalismo, publ. en Neoconstitucioalismo, Edición de Miguel Carbonell. Editorial Trotta, $2^{\circ}$ Edición. Madrid, España.

Oteiza, E. (2018). Reformas procesales en América Latina. Tendencias y tensiones entre los Estados Nación y la Comunidad Internacional, publ. en Sendas de la reforma de la justicia a principios del Siglo XXI, Coordinador Eduardo Oteiza. Editorial Marcial Pons. Madrid, España.

Pabón Giraldo, L. (2017). El juez como gerente del proceso civil: reto en la nueva tendencia del derecho procesal contemporáneo, publ. en Tendencias contemporáneas del Derecho Procesal, Dir. Velandia Canosa, E. Universidad Libre. Bogotá, Colombia. (519-539).

Pereira Campos, S. (2010). El proceso civil ordinario por audiencias: la experiencia uruguaya, publ. en Libro Memorial del XXXI Congreso Colombiano de Derecho Procesal. Universidad Libre, Bogotá, Colombia.

Pérez Luño, A. (2006). La tercera generación de derechos humanos. Editorial ThompsonAranzadi. Navarra, España.

Vega, J.C. (2006). Los Derechos humanos: idea política, metodología de análisis crítico, legalidad supranacional, publ. en Derechos Humanos: legalidad y jurisdicción supranacional. Dir. Juan Carlos Vega. Editorial Mediterránea. Córdoba, Argentina. 
Villalba Bernié, P.D. (2019). Litigación oral, los desafíos para un nuevo proceso civil. Ediciones Nueva Jurídica. Bogotá, Colombia.

Códigos comparados

Código General del Proceso, del Uruguay (1988).

Código General del Proceso, de Colombia (2012).

Código Procesal Civil, de Costa Rica (2015)

Código Procesal Civil, de Bolivia (2013)

Código de Processo Civil, de Brasil (2015)

Jurisprudencia

Corte IDH, Caso Villagrán Morales y otros (Casos de los Niños de la calle) vs Guatemala, Sentencia del 19/11/1999 (Ser. C), Nº 63.

Corte IDH, Caso Hilaire, Constantine y Benjamin y otros vs Trinidad y Tobago, sentencia 21/06/2002.

Corte IDH, caso Ortiz Hernández y otros vs Venezuela, Sentencia 22 de agosto de 2017.

Corte IDH, Opinión Consultiva, OC-4/84 del 19 de enero de 1984 (Ser. A) Nº 4.

Datos obtenidos de internet

https://www.vanderbilt.edu/lapop/survey-data.php, del 2014. 